\title{
ANALYSIS OF THE VELOCITIES OF ESCAPED SAVINGS WITH THAT OF FINANCIAL LIQUIDITY
}

\author{
Constantinos Challoumis \\ National and Kapodistrian University of Athens, Greece
}

Corresponding: challoumis_constantinos@yahoo.com

Recceived: 24.08.2018; Accepted: 23.11.2018

\begin{abstract}
This paper analyzes the impact factors of financial liquidity and of escaped savings of the economy. These two elements are important for the economy as determine its robustness. It has been comparedfor the purposes of this paper, the velocity of escaped savings with the velocity of the financial liquidity to be able to extract the appropriate conclusions, about their behavior to the economy, through the use of cycle of money. Then, we obtained about these velocities their impact on the economy. The form of the escaped saving with the financial liquidity determines the dynamic of the economy. In this scrutiny has been examined the case that the financial liquidity is higher than the case of the escaped savings. According to those conditions has concluded the behavior of the economy to this economic circumstances. In addition, the method which used is the Q.E. methodology.
\end{abstract}

Keywords: velocity of escaped savings; velocity of financial liquidity; tax and public policies; controlled transactions; MNEs

\section{Introduction}

The financial liquidity and the escaped savings are in a strong relationship between them. The velocities of the escaped savings and the financial liquidity connect these two terms. This work analyzes the case of the cycle of money with the velocity of financial liquidity with the velocity of escaped savings. Then, in this scrutiny are used the basic principles of the cycle of money which some of them are included in the next two sections, for the purposes of this analysis. Thence, using the Q.E. method extracted 
conclusions, about the importance of these velocities in the economy. Additionally, using this scrutiny is clarified the relationship between the velocity of escaped savings, with the velocity of financial liquidity. The relation of escaped savings and of the financial liquidity appears through these economic velocities.

\section{Methodology}

The methodological approach which used in this paper comes from the theory of axiomatics and of the multiple axiomatics. Hence, it is applied the Q.E. method. The quantification method of this methodology has used to extract conclusions about the behavior of financial liquidity with the escaped savings from the economy. [Challoumis, 2018g] Therefore, we are able to proceed to the allocation of profits and losses of the companies, which participate in controlled transactions.

The key factor of the method of axiomatics is in the issue of the assumptions. The axiomatics stands on the assumption for the research to the most economic approaches. The concept of the axiomatics is the compliance between the results and the initial hypothesis. Initially, to the first steps of the research, the scientist should determine the aims and the scope of the researchwithout knowing the result of one hypothesis. The hypothesis of an economic theory is the axis for the further study of each economic model which is under examination. Therefore, the axiomatics is trying to answer to the background of an economic analysis and to confirm that the initial hypothesis of the model is satisfied. The reliability of the model is subject to the consistency of the hypothesis of the results. If the hypothesis is satisfied then the model is fine with the principles of the model that is under examination. The mainstream idea of the Q.E. theory is based on a methodology which uses the clarification of mathematic equations subject to conditions which also be considered. Inasmuch as the dependent variables revealthe behavior of the selected model. The generator produces random values which determine the attributes of the dependent variable. This procedure is integrated with the independent variables which interactwith them. The dependent variables determine the behavior of the independent variables. Therefore, we have two cases:

- The analysis of the behavior of the model.This analysis is the source of the determination of the behavior of the model. This 
approach is used for the comparability analysis of the model.

- The frequency analysis behavior. This scrutiny is about the behavior of the dependent variables tithe independent variables. The basis of this procedure is about the number of appearances between the equations which are under consideration. Shows the impact of the determined model through the comparisons between different facets. [Challoumis, 2018f]

Thence, the Q.E. methodhas fourcrucial steps. Thence,the steps are these:

- The first step is about the assumptions which make the scientist initially for the model. The assumptions are in the same line with the scope of the examination of the model. These assumptions or hypotheses are connected with all steps. The assumptions are connected with the second step of the generator, where the model is studied. Moreover, this affiliated with the conclusions, as at his stage the scientist confirms the reliability and sustainability of the model.

- The second step is about the generator. To this step, the generator produces the values for the independent variables, with the purpose to clarify the behavior of the dependent variables. The clarification of the behavior of the dependent variables with their turn clarifies the behavior of the mode. Inasmuch as the procedure needs at least two mathematical equations. Then, the procedure is based on the lack of the addition of some variables. Therefore, it is plausible to determine the behavior of the model. This behavior is determined by (i) the analysis of the behavior of the model and (ii) by the frequency analysis of the model.

- The third step is about the conclusions. If the conclusions comply with the initial assumption of the first step, then the model is reliable. But, if the initial hypotheses and the results are not in the same line, the procedure continues. This means that the scientist proceeds through the fourth step, of the feedback.

- The feedback is about the fourth step. This step permits the remodification of the model until to find its' appropriate form.

The scheme for this procedure is represented below: 


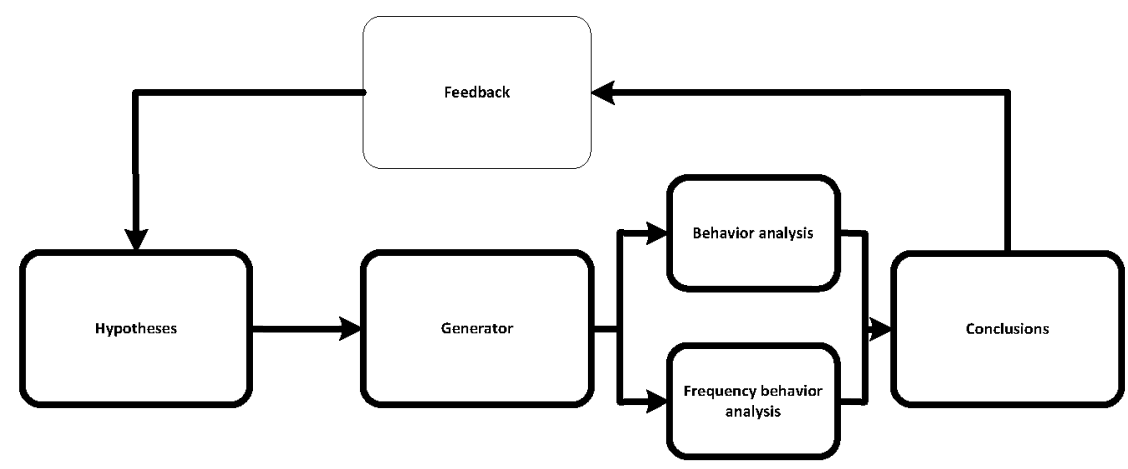

Figure 1: Q.E. procedure

Thereupon, from the prior figure of the Q.E. procedure, we obtain the mechanism which has been described to upper through the four steps of the clarification of the model. Thence, using that methodology is plausible to clarify the model.

\section{Allocation of profits and losses}

The allocation of profit and loses entered the international economics the role of the multinational enterprises. The world tradehas affected by these allocations. The companies which are responsible for these allocations are the multinational enterprises, known as MNEs. The MNEs then are about the companies which participate in controlled transactions. The growth of the MNEs caused a complex taxation system. The tax administration and the MNEs have a complexity which came from the multinational rules. The fact is that each country has separate rules for the companies which participate in controlled transactions. Then, the importance of adoption of international rules from the countries is crucial for the taxation of the MNEs. The contracts and the agreements between the participants of control transactions are these which determine the allocation of profits and losses. To the agreements should be mentioned the changes in the contracts. This is the reason why the tax authorities should make periodic inspections. The periodic specification of contracts is crucial for the comparability analysis. These periodic inspections of the companies which participate in controlled transactions are significant for the arm's length 
principle. Then, the determination of the cost sharing depends on the periodic check of companies which are tested parties. ${ }^{1}$ The scope of the companies of controlled transactions is to face the issues that are connected with the taxation of their activities. Therefrom, the requirements for the companies of controlled transactions with the tax authorities should be in the range of the arm's length principle. Thereupon, the adequate agreements of the companies of controlled transactions are those which permit them the maximization of their profits in tax environments with low tax rate and the maximization of costs in economic environments with the high tax rate. But, the MNEs need to comply with the regulations of the law of the public and tax authorities agreements. The international taxation principles of the OECD member countries serve the objectives of the authorities. Therefore, is plausible the avoidance of the double taxation, thereby minimizing the conflicts between different tax systems. Thereupon, the international trade is promoted by the implementation of these tax agreements of the OECD countries. The purpose of the world trade through a multilateral and nondiscriminatory axis permits the global economic growth. But, from the practice has been proven that the transfer pricing methods of companies are used with that way to minimize their losses and to maximize their utility, by tax evasions.

The mutual agreements between the governments govern the resolution of transfer pricing cases between the OECD member countries. The article 9 of the OECD about the model tax convention shows that the requested adjustment should comply with the principles of tax transactions. Then, the competent authorities are expected to take a cooperative approach for the mutual agreements. One issue is about the allocation of the burden of proof. In most jurisdictions, the tax administrations have the burden of proof.

One more theme is the risks of the cost-sharing. The companies undertake commercial activities to make profits, but these activities are in line with risk issues. The opportunities which come from these activities are carried through uncertainty. The hypotheses of risks associated with the commercial opportunity. The allocation of risks assumed between the parties to the arrangements affects the way that transactions are allocated between these companies which participate 
Challoumis C., Analysis of the velocities of escaped savings with that of financial liquidity

in controlled transactions. Thence, the authorities should take undermine that the comparability procedure between the controlled and the uncontrolled transactions are subject to multiple factors and not only between profits and losses.

Moreover should be notified that the companies of controlled transactions and at the same time the inspections of tax authorities are done under the condition of the proportional

IChalloumis, $2018 \mathrm{e}]$ adjustments. interpretation of the condition of the proportional adjustments is that the companies which participate in controlled transactions many times don't have the appropriate data and uncontrolled transactions of similar circumstances to compare and therefore they adjust their data with proportional way. This means that if the companies which are tested parties conclude that the profits and losses of companies from uncontrolled transactions are much higher or much fewer then they make a proportional analogy to compare them with their data. Both tax administrations and taxpayers face difficulties in perceiving adequate information to apply the arm's length principle. The reason for this situation is that the arm's length principle requires from the authorities and the taxpayers to estimatethe uncontrolled transactions, with a lack of data. In any case, the subject of these activities is based on the production of goods and services. Thence, the production of goods and/or services creates profits and costs for the enterprises. [Challoumis, 2018d] Forasmuch asfrom the prior scrutiny, we have that: [Challoumis, 2018c]

$u=s(z f+\tilde{z} d)$

$z=|\tilde{z}-1|$

According to the prior equations presented their interpretations. The symbol $u$ is about the impact factor of the comparability analysis which has any method to thes. The symbol $\mathrm{z}$ is a coefficient which takes values between 0 and 1 . What value could receive is determined by the influence of the method (using the best method rule) to thes. The symbol of $f$ is about the cost which comes up from the production of goods, and the symbol of $d$ is about the cost which comes from the distribution of the goods. Then through these expressions, we havethe costs of production and of distribution of goods in relevance with the tax rate. These conditions show that the method which the companies choose to influence thtoe factors of the $f$ and of $d$. Thence, the best 
method rule has a significant impact to the comparability analysis. According to equations from (1) to (2) is plausible to determine the following equations:

$u_{c}=z f+\tilde{z} d$

$\mathrm{b}=\left(\mathrm{p}-u_{c}\right)^{*} j_{1}$

Therefore, we have the next symbols. The symbol of $b$ in the prior equation is about the amount of taxes that should pay the companies of controlled transactions in the application of the arm's length principle. The symbol of $u_{c}$ is about the amount of tax obligations that companies can avoid through the allocations of profits and losses. Moreover, the of symbol $j_{1}$ is about the coefficient of tax. Then, the equation (4) shows the case of the arm's length principle. The authorities tax these amounts, which companies of controlled transactions present to them. In addition to the case of fixed length principle we have the next equation:

$v=\mathrm{p}^{*} j_{2}$

The symbol of $v$ to the previous equation shows the taxes that should pay the enterprises of controlled transactions in the application of the fixed length principle. Then, $j_{2}$ is a coefficient for the rate of taxes in the case of fixed length principle. Thence, the authorities set a minimum rate of allocations to the controlled transaction. The knowledge of the behavior of the MNEs has showed that the OECD member countries have an orientation to face the tax evasion of companies of controlled transections. Thereupon, we obtain according to the priortheory that:

$v \geq b$

The fixed length principle secures that the MNEs should pay for their allocation of profits and losses, a minimum rate of tax. Inasmuch as, the companies which participate in controlled transactions because of the flexibility that they have by the use of the best method rule, have minimum obligations to the authorities. The tax for the companies which participate in controlled transactions of transfer pricing in the case of fixed length principle is higher or at least equal with that of the case of the arm's length principle. Thence, the fixed length principle uses a minimum security tax level for its approach. Thereupon, with the fixed length principle the enterprises of controlled transactions are able to tackle issues which come from the allocation of the profits and losses. Thence, the tax authorities are able to face the transfer pricing effects to the global tax revenue. The fixed length principle permits to recover the tax losses of the global tax 
Challoumis C., Analysis of the velocities of escaped savings with that of financial liquidity

revenue from the controlled transactions of the transfer pricing. The fixed length principle admits a minimum allocation through the international practices of these enterprises. The advance of the choice of the tax the method which have the MNEs servesas the best way the allocation of profits and losses. Hence, withthat way, the companies of uncontrolled transactions are discriminated.

\section{The cycle of money and the ideal approach of the cycle of money [Challoumis, 2018]}

In this section are analyzed issues about the theory of cycle of money and of the theory of ideal cycle of money. Thence, the tax revenues correspond to the savings that the enterprises could have if the taxes were avoided. The way that these savings are administrated is different from case to case. Then the benefits of the companies could be managed in a completely different way, as could be saved or could be taxed. The theory of the cycle of money shows when the savings enforce the economy and when the taxes robust the economy. It is critical for this clarification to be a separation of savings into the non-returned savings (or escaped savings) and into the returned savings (or enforcement savings). For the scope of this analysis below are demonstrated the equations which are:

$\alpha=\alpha_{s}+\alpha_{t}, \dot{\mathrm{\eta}}, \frac{1}{v}+\alpha_{t}$

$x_{m}=m-a$

$\mathrm{m}=\mu+\alpha_{p}$

$\mathrm{\mu}=\sum_{\iota=0}^{n} \mu_{\imath}$

$\alpha_{p}=\sum_{j=0}^{m} \alpha_{p j}$

$c_{m}=\frac{d x_{m}}{d a}$

$c_{\alpha}=\frac{d x_{m}}{d a m}$

$c_{y}=c_{m}-$ cthe $_{a}$

The variable of ahas symbolized the case of the escaped savings. This means that we have savings which are not returned back to the economy or come back after a longterm period. The variable of $\alpha_{S}$ symbolizes the case that we have escaped savings which come from transfer pricing activities. The variable of $\alpha_{t}$ is symbolizes the case that we have escaped savings not from transfer pricing activities but from any other commercial activity. For instance $\alpha_{t}$ could refer to the commercial activities which come from the uncontrolled transactions. The variable of $m$ symbolizes the financial liquidity in an economy. The variable of $\mu$ symbolizes the consumption in an economy. The 
variable of $\alpha_{p}$ symbolizes the enforcement savings, which come from the citizens and from small and medium sized enterprises. The variable of $x_{m}$ symbolizes the condition of financial liquidity in an economy. The variable of $c_{m}$ symbolizes the velocity of financial liquidity increases or decreases. The variable of $c_{\alpha}$ symbolizes the velocity of escaped savings. Therefore, the variable of $c_{y}$ symbolizes the term of the cycle of money. Thereupon, the cycle of money shows the level of the dynamic of the economy and of its robustness. The cycle of money shows the situation of the economy. It presents the level of the wellstructured tax system and in general the dynamic of the economy. If this indicator has a high value the economy has increaseda its'dynamic. The cycle of money consisted of two factors, as the equation (14) shows there is the velocity of financial liquidity and of the escaped savings. The velocity of financial liquidity shows how rapidly the economy robustness grows or declines accordingly. The velocity of escaped savings shows how rapidly the non-return savings are lost from the market, or by the lack of investments, or by the lack of consumption. As uncontrolled transactions in the theory of cycle of money are the case of commercial activity of citizens, the small and medium-size enterprises, the factories, the research centers, and any kind of commercial activity that cannot substitute by the companies of controlled transactions. On the other hand, the controlled transactions in the theory of cycle of money are considered not only to the cases of transfer pricing but at any kind of administration of allocations to avoid taxation. There are some impact factors about the rewarding taxes. The rewarding taxes are the only taxes which have a significantimpact in the market of any economy. These factors are affiliated with:

- The first rewarding tax is about the education

- The second rewarding tax is about the health system

- The third rewarding tax is about the rest of the relevant structural economic factors of the previous two impact factors. Thence, the rest rewarding impact factors are elements which are connected with secondary or supportive activities to the education and to the health system.

Based on that analysis, we have the scheme below: 


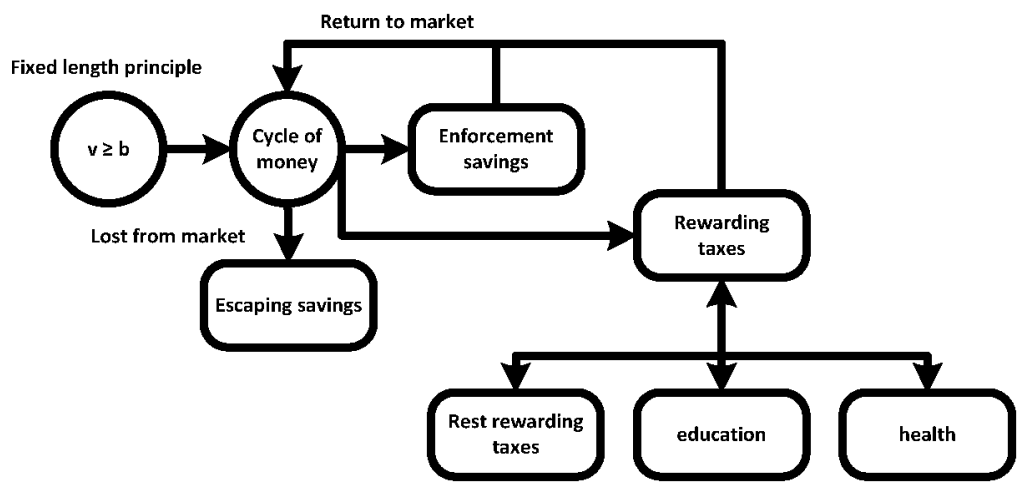

Figure 2: The cycle of money with rewarding taxes

In the prior imagies presented the case that in the tax system are considered all the tax factors and with all the rewarding tax factors. The rewarding taxes have the special characteristic that the taxes return immediate to the economy, enforcing its dynamic and then its robustness. The theoretical scrutiny and the mathematical approach is used the Q.E. method to extract conclusions about the behavior of this model.

\section{Mathematical and theoretical analysis}

In this section, we have the mathematical approach of the prior scrutiny, about the cycle of money with the velocity of escaped savings and the velocity of financial liquidity. For the purposes of the mathematical approach of the cycle of money we use the prior equations subject to the next condition:

$\mu>\alpha_{p}>\alpha_{t}>\alpha_{s}$

Therefore, we use the equation from (6) to (15) and the next table for the coefficients of the values of the cycle of money. Thence, the following table uses the values for the generator, which produce random numbers for the clarification of the model, using the fuzzy logic theoretical background of the Q.E. theory. Then, we have that:

\begin{tabular}{ll}
\hline Factors & Values \\
\hline $\mathbf{a}_{\mathrm{s}}$ & 0.6 \\
$\mathbf{a}_{\mathrm{t}}$ & 0.7 \\
$\mathrm{u}$ & 0.9 \\
$\boldsymbol{\alpha}_{\mathrm{p}}$ & 0.8 \\
\hline
\end{tabular}

Table: Compiling coefficients 
The randomization process of the generator clarifies the model. The generator of this procedure used the coefficients which appeared on the previous table. Therefrom, the factors have an upper limit of 1 , and a lower limit 0 , but $s$ and $\tilde{s}$ are plausible to receive values greater than one as their mathematical structure allow this. After 461 iterations of the model using the conditions of the equation (15) extracted the following diagram:

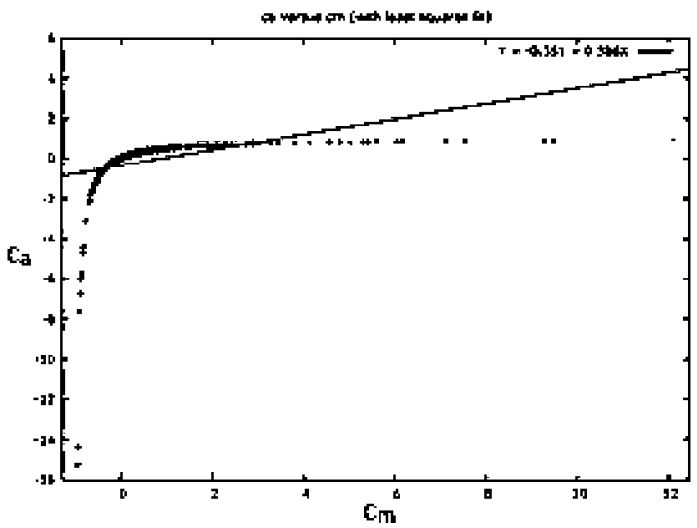

Figure 3: Velocities of escaped savings and of financial liquidity

According to the prior figure, the velocity of financial liquidity is growing much faster than the velocity of the velocity of the escaped savings. This shows that under normal economic circumstances the dynamic of any economy is positive. Then, the dynamic of the economy is increased when there the rate escaped savings is lower than the rate of financial liquidity. Therefore, we conclude that the relation of the economic velocities under the conditions of equation (15) is determined by the next equation:

$$
c_{a}=\ln \left(c_{m}\right)+c
$$

To the prior equation, csymbolizes a constant. Therefore the equation between the equations (14) to (16) determines the relation of the cycle of money:

$$
c_{y}=c_{m}-\ln \left(c_{m}\right)-c
$$

$c_{m}+c>\ln \left(c_{m}\right)$

Thereupon, we have that when the financial liquidity is higher than the escaped savings, then the cycle of money and therefore the dynamics of the economy is increased with that form. Then, 
when in the economy the enforcement savings are higher than the escaped savings, the cycle of money grows under a logarithmic form. The velocity of escaped savings increases with a logarithmic form, but the financial liquidity increases proportionally, without logarithm increase. Then, the result is the growth of the economy. The interpretation of this economic situation is that the economy is robust when the savings are not lost in the economy but are invested or used for consumption. Thence, if the money for this procedure is saved and reused and not excluded from the economy, to savings that are not re- $^{-}$ inputted, then the dynamic of the economy would be empowered. Inasmuch as the appropriate combination of financial liquidity with the savings leads the growth of the economy.

\section{Conclusions}

To this paper has shown that the economy has a positive dynamic when the authorities give to the society an appropriate economic environment. Thence, when the financial liquidity of the economy is higher than the escaped savings, the cycle of money has a positive impact on the economy. Then, the consumption and the investments in this economy will be in the high level. Therefore, the adequate tax regulations by the authorities empower the economy. The public and tax authorities when modifying the savings which are used inside the economy and not excluded from the limits of the economy the economic dynamic is enforced. Forasmuch as the increase in the consumption and of the investments minimizes the escaped savings and simultaneously maximizes the financial liquidity.

\section{Literature}

Ariely, D., Loewenstein, G. \& Prelee, D. (2003): Coherent arbitrariness: stable demand curves without stable preferences. Quarterly Journal of Economics(118), 73-105.

Boland, L. A. (1991): The Methodology of Economic Model Building. London and New York: Routledge, 0-415-06462-7.

Camerer, C. F. (2003): The behavioral challenge to economics: Understanding normal people. Federal Reserve of Boston meeting "How Humans Behave", Caltech, Pasadena CA 91125, 1-34.

Challoumis, C., (2017): Quantification of Everything (a Methodology for Quantification of Quality Data with Application and to Social and Theoretical Sciences), Available at SSRN: 
https://ssrn.com/abstract $=313601$

4, November 12, 2017

Challoumis, C. (2018): Methods of Controlled Transactions and the Behavior of Companies According to the Public and Tax Policy, ECONOMICS, 6(1), 3343.

doi:

https://doi.org/10.2478/eoik-2018$\underline{0003}, \mathrm{fn} .7$.

Challoumis, C., (2018a): Controlled Transactions Under Conditions. Available at SSRN: https://ssrn.com/abstract $=313774$ 7, March 10, 2018

Challoumis, C., (2018b): Intangible Controlled Transactions, Available at SSRN: https://ssrn.com/abstract $=314002$ G, March 13, 2018

Challoumis, C., (2018c): Analysis of Tangibles and Intangibles Transactions Subject to the Fixed Length Principle. Available at SSRN: https://ssrn.com/abstract $=314296$ $\underline{O}$, fn. 5., March 17, 2018

Challoumis, C., (2018d): Arm's Length Principle and Fix Length Principle Mathematical Approach, Available at SSRN: https://ssrn.com/abstract=, fn. 4., March 23, 2018

Challoumis, C., (2018e): The Theory of Cycle of Money Available at SSRN: https://ssrn.com/abstract $=314915$ $\underline{6}$

or

http://dx.doi.org/10.2139/ssrn.314 9156, fn.3, 6., March 25, 2018

Challoumis, C., (2018f): Analysis of Axiomatic Methods in Economics. Available at SSRN: https://ssrn.com/abstract $=316808$ $\underline{7}$

or

http://dx.doi.org/10.2139/ssrn. 316 8087, (April 24, 2018)

Challoumis,

C., $(2018 \mathrm{~g})$ : Comparison between the Velocities of Escaped Savings with than of Financial Liquidity, Available at SSRN: https://ssrn.com/abstract $=316981$ Z

http://dx.doi.org/10.2139/ssrn.316 $\underline{9817}$, fn. 1., April 27, 2018

Ernst \& Young (2000): Transfer Pricing at-a-Glance Guide. Ernst and Young, Rotterdam.

Feinschreiber, R., (2004): Transfer Pricing Methods An Application Guide, John Wiley \& Sons, New Jersey

Meier, B. D., \& Rosenbaum, D. T. (2000): Making single mothers work: Recent tax and welfare policy and its effects. National Tax Journal, 53(4), 1027-1061.

Wildasin, D., (1991): Some rudimentary "duopolity" theory, Regional Science and Urban Economics, 21, pp. 317-331 
Challoumis C., Analysis of the velocities of escaped savings with that of financial liquidity

Wilson, J.D. (1986): A theory of Recommendations by the interregional tax competition, Committee on Fiscal Affairs. Journal of Urban Economics, 19 OECD, Paris.

(3) (1986), pp. 296-315

OECD(1991): Taxing Profits in a Global EconomyOECD, Paris

OECD (1999): The OECD STAN

Database for Industrial Analysis. OECD, Paris.

OECD (2000): Towards Global Tax Cooperation. Report to the 2000 Ministerial Council Meeting and

OECD(2001): Transfer Pricing Guidelines for Multinational Enterprises and Tax Administrations OECD, Paris

OECD (2017): Transfer Pricing Guidelines for Multinational Enterprises and Tax Administrations 2017, OECD Publishing, Paris.

1 As tested parties considered the companies which participate in control transactions. 